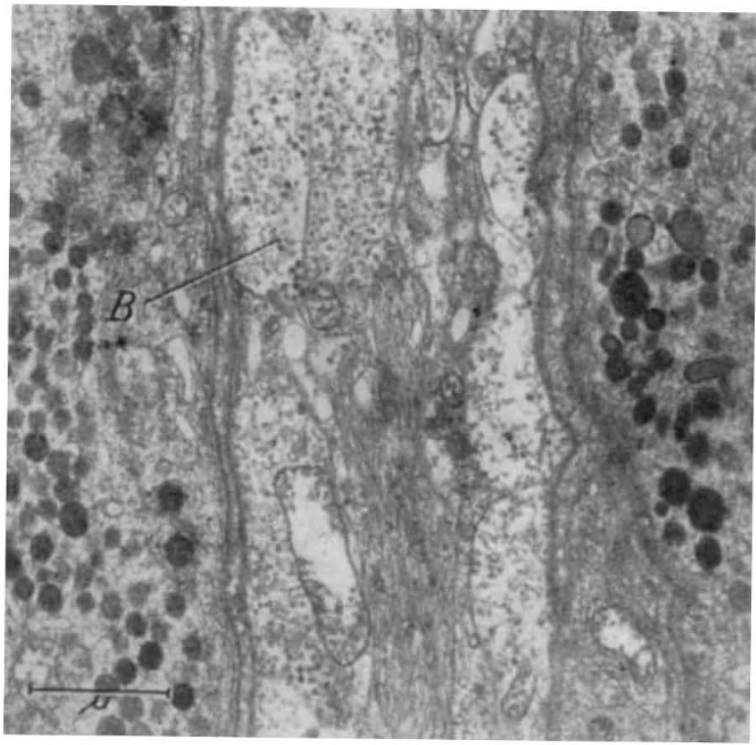

Fig. 1. Electron micrograph of a portion of the rostral pars distalis of an of pCTH about $700 \AA$ in diameter

There is evidence, therefore, at the level of ultra-structure for a neurosecretory innervation of the pars distalis of the eel by at least two kinds of neurosecretory fibre, and that the activity of one fibre type (Type $A$ ) may be correlated to stages of the life-cycle.

Francis Knowles

Lutz Vollrath.

Department of Anatomy, Medical School,

University of Birmingham.

${ }^{1}$ Bargmann, W., Z. Zellforseh., 38, 285 (1953).

${ }^{2}$ Knowles, Sir F., and Vollrath, L., Z. Zellforsch., 69, 474 (1966).

${ }^{3}$ Knowles, Sir F., Phil. Trans. Roy. Soc., B, 249, 435 (1965).

‘ Bern, H. A., and Knowles, Sir F., in Neuroendocrinology, edit. by Martini, L., and Ganong, W. F. (Academic Press, New York, 1966).

\section{Control of Furunculosis in Impounded Adult Salmon}

From July 27 to August 17, 1964, 17 salmon were found dead among about 40 fish impounded at Ceannacroc on the Moriston, a tributary of the River Ness. Eight salmon examined between August 1 and 14 showed typical symptoms of furunculosis, and pure cultures of the causative organism, Bacterium salmonicida, were isolated from the internal organs and muscle. As a serious outbreak of furunculosis had occurred in this impoundment and at another impoundment on the Ness system in 1963, an attempt was made to control the outbreak which seemed to threaten this year.

It was decided to use an intramuseular depot injection, so as to maintain the highest blood levels of antibiotic for the longest time after a single injection. Chloramphenicol was chosen as the antibiotic since it is known to be effective against $B$. salmonicida both in vitro and in vivo ${ }^{x}$. Chloramphenicol has a low solubility in water so that an aqueous suspension would provide a depot in the muscle which would be dissipated slowly. 'Intramycetin', a veterinary preparation containing 15 per cent chloramphenicol in aqueous suspension (Parke Davis and Co.), was used at a rate of $1 \mathrm{ml} . / 15 \mathrm{lb}$. of fish. At this rate, a single intramuscular injection of this preparation should supply effective blood levels of chloramphenicol for 24$48 \mathrm{~h}$.

All the impounded fish were treated on August 17. The fish were injected on the left side slightly anterior to the dorsal fin and towards the heart and coelom, the needle being inserted to its full extent. Sterile disposable plastic syringes were used, with needles 21 gauge, 1.5 in. long. A total of 44 fish was treated, including seven fish which were being transferred to the impoundment from the trap nearby.

Two fish died within a few hours after the injection. These were in a decidedly poor condition before treatment, and handling and injection may have hastened their death. Two more fish died later, one on September 6 and one on Oetober 9 . Unfortunately it was not possible to examine any of these fish after death. Following the treatment given on August 17, ton more fish were added to the impoundment from the trap. All these were injected before being placed in the impoundment and thoy, and the other fish impounded, have apparently remained healthy and normal.

It should be emphasized that this treatment was devised to meet an emergency, but the results obtained suggest that a rigid experimental investigation would confirm the results of this ad hoc test. If this should be so, the treatment has a number of advantages: it is easily carried out and can readily be taught to non-technical staff; it seems to have no adverse effect on the fish; and it is inexpensive, as it is estimated that 50 fish could be treated for less than $£ 5$.

I thank Mr. J. Wood, superintendent to the Ness District Fishery Board, and his staff, for their help.

Department of Agriculture and

Fisheries for Scotland,

Marine Laboratory,

Victoria Road, Aberdeen.

* Present address: Botany Department, University College of Wales, A berystwyth.

${ }^{1}$ Snieszko, S. F. United States Department of the Interior, Fishery Leaflet 467 .

\section{Action of Gibberellic Acid on Auxin Transport}

THE polar transport of $\beta$-indolylacotic acid (IAA) in plant organs has been known since the observations of Went ${ }^{1}$ and van der Weij ${ }^{2}$. Most of the direct investigations of IAA movement have used bioassays for detecting auxin $^{3}$. But these analyses have been limited by the sensitivity of the method ${ }^{4}$. The recent use of IAA labelled with carbon-14 (IAA*) facilitates the study of the auxin translocation ${ }^{5}$.

It has been previously observed that, in the stem sections of Lens culinaris, there is a predominantly basipetal movement of carbon-14 from applied IAA*. It has been assumed that gibberellic acid (GA) increases the uptake of IAA * and changes the auxin transport in these sections ${ }^{6}$. In the present communication, the action of GA on the velocity of IAA* translocated in the section of the stem of Lens culinaris Med. will be discussed.

The movement of IAA * $\left({ }^{14} \mathrm{C}\right.$-labelled in the carboxyl group: specific activity of $8 \mathrm{mc} . / \mathrm{mmole}$ ) has been examined in 6-mm sections, using the technique of McCready ${ }^{7}$ and Pilet ${ }^{8}$. The agar $\left(1.5\right.$ per cent) blocks were $16.6 \mathrm{~mm}^{3}$ in volume. The donors contained 5 or $50 \mu$ moles of IAA *. At the end of each experiment, each set of forty replicate blocks was pooled for the analysis of their radioactivity - these were expressed in counts per min (c.p.m.) per mg of dry weight.

Seeds were soaked for $4 \mathrm{~h}$ and then placed in Petri dishes on filter paper with de-ionized water for $24 \mathrm{~h}$. Seedlings were then selected $(4 \mathrm{~mm}$ roots) and planted under the same conditions ${ }^{9}$. After $72 \mathrm{~h}$, when used for experimental purposes, the stems were $10 \mathrm{~mm} \pm 2 \mathrm{~mm}$ long. All experiments were carried out at $25 \cdot 0^{\circ} \mathrm{C}$, in complete darkness. During manipulation only green light was used.

The principles involved in the assay are shown diagrammatically in Fig. 1. After an incubation of $2 \mathrm{~h}$ in Ringer's solution containing (or not) GA, the sections (40 for $25 \mathrm{ml}$.) 